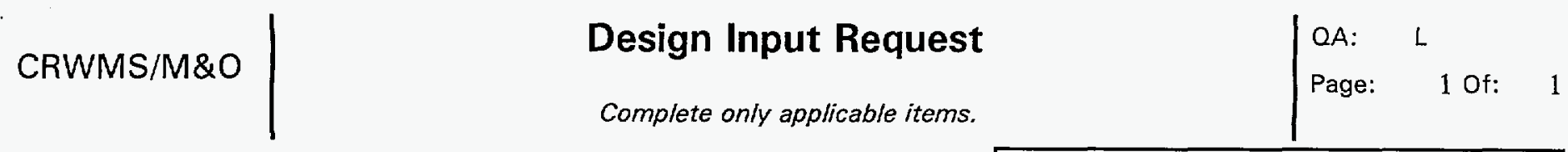

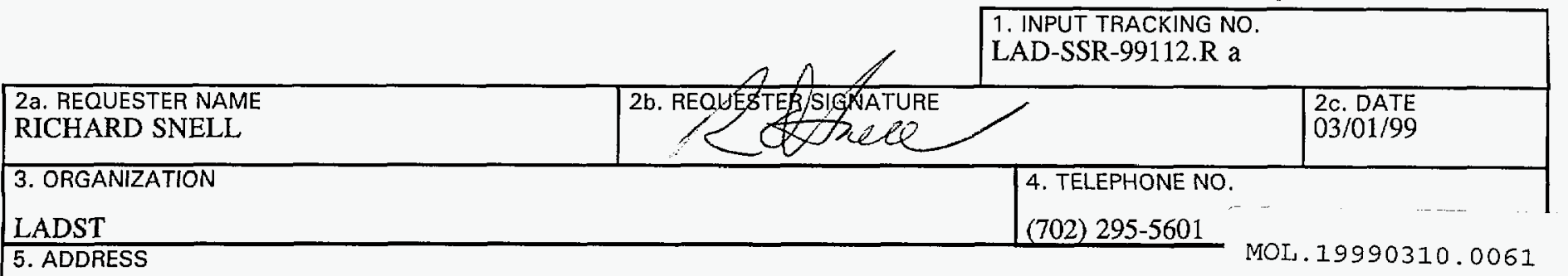

1261 TOWN CENTER DRIVE, LAS VEGAS, NV 89134 MS-423

6. DESCRIPTION, TITLE, SUBJECT

LADS PHASE II EDA EVALUATIONS

7. NEED DATE OF DESIGN INPUT

8. DESIGN INPUT NEEDED FOR WORK SUBJECT TO QARD REQUIREMENTS

$04 / 15 / 99$

$\square$ Yes $\square$ No

9. SCOPE OF DESIGN INPUT REQUESTED (Name of document(s), if known):

THE PURPOSE OF THIS QAP-3-12 REVISION IS TO PROVIDE THE FOLLOWING:

1. REVISED LADS PHASE II EVALUATION CRITERIA REV 01 2/23/99 (4 PAGES ATTACHED )(REPLACES REV 00 2/3/99 IN IT'S ENTIRETY)

2. CHANGE SCHEDULE DATE FOR TRANSMITTAL (VIA QAP-3-12 TRANSMITTAL) OF BEST AVAILABLE INFORMATION FROM 2/22/99 TO 2/26/99.

3. CLARIFICATION - AS STATED IN NOTE 1 OF THE LADS EDA TABLE REV 00 2/4/99 THE GOALS ARE TO BE CONSIDERED THE CONTROLLING BASIS OF THE DESIGNS. THE PARAMETERS ARE EXPECTED TO EVOLVE DURING THE EVALUATION. CONSEQUENTLY THE SPECIFIC PARAMETERS STATED IN THE TABLE AS WELL AS IN THE NARRATIVE PRELIMINARY DESCRIPTIONS ARE TO BE CONSIDERED STARTING POINTS AND WILL BE FINALIZED IN THE SPECIFIC EDA QAP-3-5 TECHNICAL DOCUMENTS.

4. ALL OTHER REQUIREMENTS REMAIN UNCHANGED.

10. DESCRIPTION OF INTENDED USE OF DESIGN INPUT:

UNCHANGED

To:

11a. RESPONSIBLE MANAGER NAME

DANIEL MCKENZIE

11b. ORGANIZATION
SUBSURFACE DESIGN

11c. TELEPHONE

(702) $295-4393$

11d. ADDRESS

1261 TOWN CENTER DRIVE, LAS VEGAS, NV, MS-423 


\section{LADS PHASE 2 EVALUATION CRITERIA}

2/23/99

Rev. 01

The following evaluation criteria are for the evaluation of Enhanced Design Alternatives (EDAs). In order to gain some indication of the uncertainty associated with each assessment, the "confidence" should also be included (scale of 1 to 5, as in Phase 1).

\section{SCREENING CRITERION}

The following screening criterion are deemed to be necessary for any EDA to be considered as a candidate for selection as the SR/LA design. As such, this criterion will be used to screen the EDAs. Any EDA that does not meet the screening criterion will be removed from further consideration, or further enhanced to ensure that it meets the screening criterion.

1. Post-Closure Performance: Defined as the peak dose rate (central estimate) within 10,000 years. The screening level is the anticipated regulatory level of $25 \mathrm{mrem} / \mathrm{yr}$ within $10,000 \mathrm{yrs}$. Note that longer-term performance is considered in the Safety/License Probability criterion.

\section{EVALUATION CRITERIA}

The following evaluation criteria will be used to evaluate the EDAs in Phase 2 of the LADS process. The measures for each criterion are also given.

\section{Safety/License Probability}

The evaluation of safety and licensability is based on a consideration of the safety margin, degree of defense-in-depth, and various factors related to the degree of engineering acceptance. Safety margin is defined as the difference between the calculated performance (central estimate) and the anticipated regulatory standard ( 25 $\mathrm{mrem} / \mathrm{yr}$ ) within 10,000 years. The uncertainties in post-closure performance and the ability to reduce or mitigate those uncertainties are also an element in assessing the license probability. To evaluate whether the design would lead to significant increases in peak dose rate beyond 10,000 years, the performance up to $1,000,000$ years is also considered. The degree of DID is an engineering judgement that multiple, diverse barriers exist over a 10,000 year and longer time periods. In addition, licensability is related to several factors defining the degree of engineering acceptance:

- The function of each element of the design can be clearly communicated

- The engineering analysis follows accepted methods

- The post-closure functions can be demonstrated

- There are regulatory and/or engineering precedents for the design and construction

$$
\angle A D \cdot S S R-991 / 2 \cdot R a
$$


- The availability of qualified data is likely in the LA time-frame, or prior to waste emplacement

- No high level design goals for the MGR (i.e., the CRD and CDA) are violated by the use of this design, or if violated the consequence of the violation is acceptable considering potential performance for the design.

- No EDA should lead to unacceptable environmental effects.

\section{Measures:}

1. The safety margin, defined as the difference between the calculated $10,000 \mathrm{yr}$ performance and the regulatory standard $(25 \mathrm{mrem} / \mathrm{yr})$.

2. A constricted scale that expresses the judgment of the degree of DID associated with the design (in terms of numbers of barriers, diversity of barriers, longer-term DID, and other considerations) (i.e., 5 represents a high degree of $\mathrm{DID}$; 1 represents a low degree of DID).

3. A constructed scale that expresses the uncertainties in post-closure performance and the ability to reduce or mitigate them within the LA time-frame (i.e., 5 represents small uncertainties or easily mitigated uncertainties; 1 represents large, irreducible uncertainties).

4. A constructed scale that expresses the degree of engineering acceptance (i.e., 5 represents high degree of acceptance; 1 represents low degree of acceptance).

5. Peak dose rate (central estimate) within $1,000,000$ years.

Summary Evaluation: An overall probability that the design will evolve to a design for the LA that is acceptable for licensing, in light of the design margin, degree of DID, postclosure uncertainties, 1,000,000-year peak dose rate, and engineering acceptance. The probability can range from 1.0 to 0 , with the following descriptors as a guide:

Probability

$0.75-1.0$

$0.75-0.55$

$0.55-0.45$

$0.45-0.25$

$0.25-0.0$
Highly likely

Reasonably likely

Equally likely as unlikely

Not likely

Highly unlikely 


\section{Cost/Schedule}

Each EDA will be evaluated for the time required and the present-day and discounted costs associated with each of the following phases: site characterization and licensing, construction, operations, monitoring, and closure.

\section{Measures}

Note: all estimates should assume a 50 year period from start of emplacement to closure.

1. The total system life cycle costs ( $\pm 50 \%$ for conceptual design) associated with each of the five phases in 1999 dollars.

2. The net present value costs associated with each of the five phases.

3. The number of years associated with each of the five phases.

\section{Construction, Operations, and Maintenance}

This criterion will be used to evaluate the particular advantages or disadvantages of an EDA in addressing construction, operations, and maintenance issues, including:

- Worker radiation safety/industrial safety

- Reliability/availability/maintainability/inspectability

- Throughput capacity

- Performance confirmation activities

- The design is constructable with proven methods

- Difficulty or ease in meeting the Design Basis Events

- Off-normal event recovery

\section{Measures}

1. A constructed scale that expresses the overall degree of advantage or disadvantage, taking into account the degree of simplicity or complexity, in addressing construction, operations, and maintenance issues (i.e., 5 expresses highly advantageous; 1 expresses disadvantageous).

\section{Flexibility}

This criterion expresses the degree to which a design would be capable of remaining viable and/or able to change in the face of future regulatory or other changes. Possible changes to consider are the following:

- Increased disposal capacity (105,000 MTU)

- A longer pre-closure period (the preferred period and up to $300 \mathrm{yrs}$ )

- Receipt of 5-yr-old SNF

- Design changes, such as:

+ Changes in fundamental designs (e.g., change from remote to human access; change from high temperature to low, or vice versa) 
+ Need to add features to enhance performance

+Desire for significantly different waste package sizes or waste streams

- Unanticipated natural features or findings (volcanism, seismic, water table rise, flooding).

\section{Measures}

1. A constructed scale that expresses the flexibility of the EDA to accommodate each of possible contingencies (i.e., 5 expresses high degrees of flexibility; 1 expresses low degrees of flexibility).

Summary Evaluation: A constructed scale that expresses the overall flexibility of the EDA to accommodate all possible contingencies (i.e., 5 expresses high degrees of flexibility; 1 expresses low degrees of flexibility). 